\begin{tabular}{|c|c|c|}
\hline & $\begin{array}{l}\text { Mobilya ve Ahşap Malzeme Araştırmaları Dergisi } \\
\text { Furniture and Wooden Material Research Journal } \\
\text { Araştırma Makalesi - Research Article } \quad 2018-1(2), 51-61\end{array}$ \\
\hline
\end{tabular}

\title{
Odunun yoğunluğu ile bazı mekanik özellikleri arasındaki ilişkinin belirlenmesi üzerine bir araştırma
}

\author{
Bekir Cihad Bal $^{1 *}$, İbrahim Bektaş ${ }^{2}$
}

\section{$\ddot{\mathbf{O} z}$}

Odunun, fiziksel, mekanik, kimyasal ve biyolojik özellikleri kullanım yeri için önemli özellikleridir. Kullanım yeri belirlenirken bu özelliklerine göre karar verilmektedir. Yük taşıyan yerlerde mekanik özelliklerinin yüksek olması istenir. Dış ortamlarda kullanılacak odunun biyolojik dayanıklılığının yüksek olması istenir. Odunun bu özellikleri üzerine; ağaç türü, rutubet miktarı, odun türü, ağaçtan alındığı yer ve odun kusurlarının etkili olduğu iyi bilinmektedir. Bu çalışmada, odunun mekanik özellikleri ile yoğunluğu arasındaki ilişki araştırılmıştır. Bu amaç için, kayın (Fagus orientalis L.) ve kavak (Populus x euramericana I214) odunları üzerinde bazı mekanik özellikler ve yoğunluk belirlenmiştir. Testlerde, odunun yoğunluğu, eğilme direnci, elastikiyet modülü, şok direnci ve basınç direnci belirlenmiştir. Denemelerde TS 2470, TS 2474, TS 2478, TS 2477 ve TS 2595 numaralı standartlar kullanılmıştır. Yoğunluk ile mekanik özellikler arasındaki ilişki regresyon denklemleri ile belirlenmeye çalışılmıştır. Bu ilişkiler dağılım grafikleri ile gösterilmiştir. Elde edilen bulgulara göre; yoğunluk miktarı arttıkça mekanik özelliklerin arttığı belirlenmiştir.

Anahtar kelimeler: yoğunluk, mekanik özellikler, kayın odunu, kavak odunu

\section{A research on the determination of the relationship between density and some mechanical properties of wood}

\begin{abstract}
Physical, mechanical, chemical and biological properties of wood are important properties for usage area. When determining usage area, it is decided according to these properties. High mechanical properties are desirable in load bearing sections. It is desirable that the biological durability of the wood used in the external environment is high. It is well known that wood species, moisture content, wood type, place taken from the tree and wood imperfections are effective on wood properties. In this study, the relationship between mechanical properties and density of wood investigated. For this purpose, mechanical properties and density were determined on beech (Fagus orientalis L.) and poplar (Populus $\mathrm{x}$ euramericana I-214) woods. In the tests, the density, bending strength, modulus of elasticity, impact strength and compression strength of wood were determined. Experiments conducted according to TS 2470, TS 2474, TS 2078, TS 2077 and TS 2595 standards. The relationship between density and mechanical properties was determined using regression equations. These relationships showed by distribution graphs. According to findings; it was determined that as the density of wood increased, mechanical properties increased.
\end{abstract}

Keywords: density, mechanical properties, beech wood, poplar wood 


\section{Giriş}

Ağaçlardan elde edilen odun hammaddesi, geçmişten günümüze, bazı ürünlerin üretilebilmesi için önemli bir hammadde ve ayrıca en önemli mühendislik malzemelerinden birisi olmuştur. Günümüzde, odun hammaddesinden elde edilen yonga levha, liflevha, heraklit, duralit, kontrplak, MDF profiller, panel kapı ve masif panel gibi kompozit yarı mamul malzemeler, mobilya ve dekorasyon işleri başta olmak üzere değişik amaçlar için kullanılmaktadır (Bal ve Bektaş 2018). Odunun fiziksel, kimyasal, biyolojik ve mekanik özelliklerinin bilinmesi, kullanım yerine karar verirken son derece önemlidir. Örneğin; mekanik özellikleri yüksek olan odun türleri yük taşıan elemanlarda, görünüş özellikleri iyi olan türler estetik bakımdan önem arz eden mobilya ve dekorasyon işlerinde kullanılmaktadır. Ekstraktif madde içeriği nedeniyle bazı türler reçine, tanen vb. üretiminde, düzgün gövde ve geniş çapa sahip türler kaplama levha üretiminde, makinelerle işlemesi kolay, maliyeti düşük olan ve kolay temin edilebilen türler doğrama sektöründe kullanılmaktadır.

Odunun fiziksel özellikleri; yoğunluk, rutubet içeriği, daralma ve genişleme özellikleri, lif doygunluk noktası, termik özellikleri, elektriksel özellikleri ve akustik özellikleri olarak siralanmaktadır (Kollmann ve Cote, 1968; Bozkurt ve Göker, 1996; Örs ve Keskin, 2001). $\mathrm{Bu}$ fiziksel özelliklerle yoğunluk arasında önemli bir ilişki olduğu yapılan önceki çalışmalarda belirlenmiştir. Örneğin; odun yoğunluğu arttıkça daralma ve genişleme yüzdelerinin arttığ (Kollmann ve Cote, 1968; Bektaş ve Güler, 2001; Pliura ve ark., 2005; Kord ve ark., 2010; Bal ve Bektaş 2018), suda bekletme sonunda ulaştığı rutubet yüzdesinin azaldığı belirlenmiştir (Bal ve Bektaş 2018). Ayrıca, termik, akustik ve elektriksel özelliklerinin değiştiği (Kollmann ve Cote, 1968) bildirilmiştir.

A ğaçlarda enine kesit incelendiğinde odun oluşumu bakımından, öz odun ve diri odun şeklinde iki farklı odun kısmının meydana geldiği ve bunun yanında genç odun ve olgun odun olarak da iki farklı odun kısmının oluştuğu bilinmektedir. Çoğu ağaç türünde genç odun kısmı öz odun kısmının ortasında kalan ve ilk 5 ile 30 yıl sonunda oluşan yıllık halkaları kapsamaktadır (Bozkurt ve Erdin 1997). Yapılan önceki çalışmaların büyük bir kısmında, test örnekleri bütün enine kesiti kapsayacak şekilde hazırlanmış ve bu öz odun-diri odun veya genç odun-olgun odun farklılıkları göz önüne alınmamıştır. Bu farklılıkları göz önünde tutarak yapılan sınırlı sayıda çalışma bulunmaktadır. Örneğin; öz odun ve diri odun kısımlarından hazırlanan test örnekleri üzerinde, morfolojik özellikler (Ay ve Şahin 1998; İstek ve ark., 2010; Bal 2012), biyolojik dayanıklılık (Çetin ve ark., 2010) fiziksel özellikler (Bal ve Bektaş 2012; Bal ve ark. 2012) ve mekanik özellikler (Bal ve Bektaş 2013) ayrı ayrı tespit edilmiş ve önemli farklılıklar ortaya konulmuştur.

Odunun bazı üstün özelliklerinin yanında üç temel yönde farklı özellikler göstermesi (anizotropi), yoğunluğuna bağlı olarak fiziksel, mekanik, kimyasal ve diğer teknolojik özelliklerinin değişiklik göstermesi ve çürümeye karşı dayanıksız olması gibi istenmeyen özelikleri bulunmaktadır. Masif ahşap malzemede yoğunluk artıkça genel bir kural olarak mekanik özellikler artmaktadır. Eğilme direnci, elastikiyet modülü ve şok direnci ile yoğunluk arasında artan-doğrusal bir ilişki vardır. Yapılan önceki çalışmalarda, birçok araştırmacı bu ilişkiyi belirlemiştir (Kollmann ve Cote, 1968; Malkoçoğlu 1994; Bozkurt ve Erdin 1995; Bektaş ve ark., 2002). Ancak, ağacın enine kesitinde, öz odun ve diri odun gibi farklı bölgelerden alınan numunelerde mekanik özelliklerin nasıl değiştiğine dair kapsamlı bir çalışmaya ulaşılamamıştır. Bu nedenle, bu çalışmada, önemli kullanım alanlarına sahip olan ve aralarında yoğunluk bakımından önemli farklılıklar bulunan kayın ve kavak odunlarında öz odun ve diri odun kısımları ayrı gruplar halinde çalışılarak yoğunluk ile mekanik özellikler arasındaki ilişkiler belirlenmeye çalışılmıştır. 


\section{Materyal ve Metot}

\subsection{Materyal}

$\mathrm{Bu}$ çalışmada, materyal olarak kayın (Fagus orientalisL.) ve kavak (Populus x euramericana I-214) odunları kullanılmıştır. Kayın tomrukları Karabük ili, Yenice ilçesinde bir kereste tüccarından ve kavak tomrukları Karabük ili, Eskipazar ilçesinde özel bir şahsa ait kavak sahasından alınmıştır. Kayın ve kavak tomruklarından test örneklerinin hazırlanacağı kısa kadronlar alınmıştır. Daha sonra bu kadronlardan mekanik özelliklerin belirlenmesi için laboratuar numuneleri kesilmiştir. Her bir test için hazırlanan örneklerin boyutları ve nasıl elde edildikleri metot kısmında anlatılmıştır. Mekanik özelliklerin belirleneceği testlerde her iki ağaç türünde, öz odun-diri odun kısımlarından test örnekleri ayrı ayrı hazırlanmıştır.

\subsection{Metot}

Yuvarlak odundan laboratuar numunesi için 60 x 60 mm kesitinde kadron kesimi Şekil 1 'de gösterildiği gibi TS 2470 'e göre yapılmıştır. Her deney için aynı tomruktan eşit sayıda kadron alınmıştır. Test örnekleri alınırken, öz odun ve diri odundan alınan test örnekleri sayısı eşit tutulmuştur. Her grup için 30 adet test örneği hazırlanmıştır.

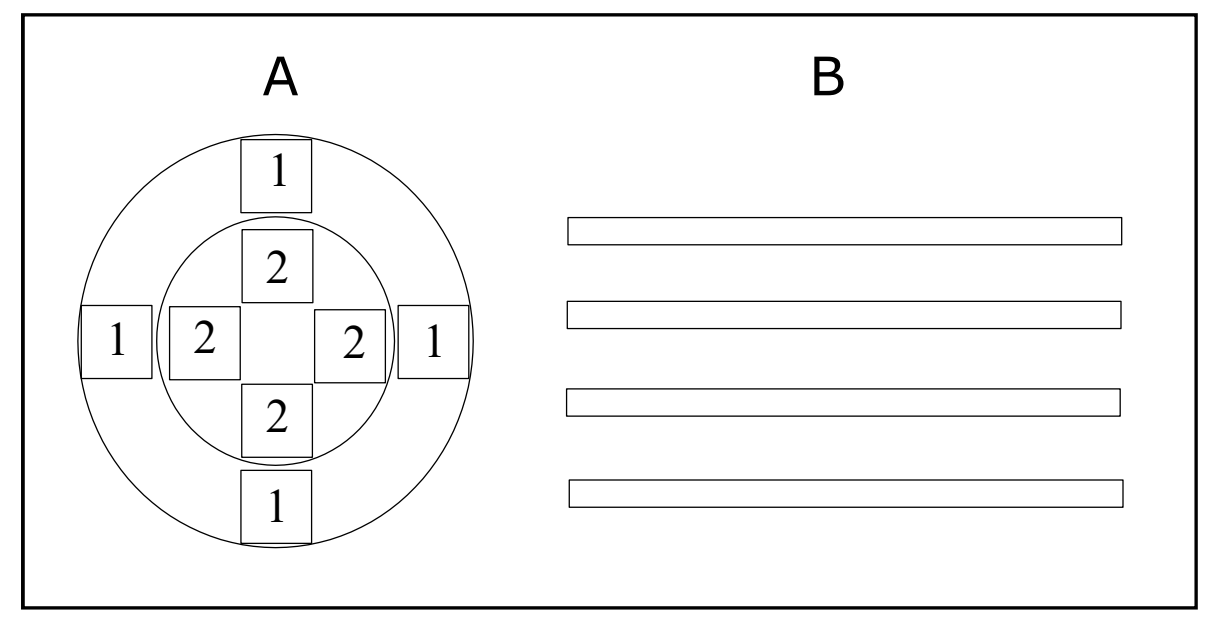

Şekil 1. Tomruk enine kesitinden öz odun (2'ler) ve diri odundan (1'ler) kadronların alınması (A), kadronlardan elde edilen test örnekleri (B)

\subsubsection{Yoğunluk miktarının belirlenmesi}

Yoğunluk ölçümleri TS 2472'ye göre yapılmıştır. Buna göre örnekler kurutma dolabına konmuş ve sıcaklığı kademeli olarak $103 \pm 2{ }^{\circ} \mathrm{C}$ 'ye çıkarılarak, yüksek 1sıda zarar görmesi önlenmiştir. Kurutma dolabında örnek ağırlıklarının sabit hale gelmesini müteakip, dolaptan çıkarılan örneklerin ağırlıkları ve üç yöndeki boyutları ölçülerek Formül (1)'e göre tam kuru yoğunluk değerleri hesaplanmıştır. Yoğunluk örnekleri, eğilme direnci ve şok direnci test örneklerinden test yapıldıktan sonra kesilip alınmıştır. Basınç direnci testinde ise, test örnekleri hava kurusu yoğunlukların belirlenmesinde de kullanılmıştır. Test örneğinin tamamında test yapılmadan önce hava kurusu yoğunluk belirlenmiştir. Sonra basınç testi yapılmıştır.

$$
\mathrm{D}_{\mathrm{o}}=\mathrm{M}_{\mathrm{o}} / \mathrm{V}_{\mathrm{o}}\left(\mathrm{kg} / \mathrm{m}^{3}\right)
$$

Burada; $D_{0}$, tam kuru yoğunluk $\left(\mathrm{kg} / \mathrm{m}^{3}\right), \mathrm{M}$, tam kuru ağırlık $(\mathrm{kg}), \mathrm{V}$, tam kuru hacimdir $\left(\mathrm{m}^{3}\right)$ 


\subsubsection{Eğilme Direnci ve elastikiyet modülünün belirlenmesi}

Eğilme direnci test örnekleri, ölçüleri 20 x 20 x 300 mm (kalınlık x genişlik x uzunluk) olacak şekilde, odunun lif yönü test örneğinin uzunluğuna paralel olacak şekilde ve yıllık halka yönü bir kenara paralel diğer kenara dik gelecek şekilde TS 2474 numaralı standarda göre hazırlanmıştır. Hazırlanan test örnekleri $20^{\circ} \mathrm{C}$ sicaklık ve $\% 65$ bağıl nem ortamında iklimlendirme yapılmıştır. Sonra statik malzeme test cihazında (Zwick Roell) test edilmiştir (Şekil 2-A). Test edilen örneklerden rutubet ve yoğunluk ölçümü için parçalar kesilmiştir. Rutubet ölçümü sonucu elde edilen rutubet yüzdeleri ile test örneklerinin rutubetleri Formül (3)'e göre \%12 rutubete tahvil edilmiştir. Deney esnasındaki rutubet miktarı M, statik eğilme direnci $\sigma_{\mathrm{SE}}$ Formül (2)'ye göre hesaplanmıştır.

$$
\sigma_{\mathrm{SE}}=\frac{3 \cdot \mathrm{P}_{\max } \cdot \mathrm{L}}{2 \cdot \mathrm{b} \cdot \mathrm{h}^{2}}\left(\mathrm{~N} / \mathrm{mm}^{2}\right)
$$

Burada; $\mathrm{P}_{\max }$ : Kırılma anında uygulanan maksimum yük $(\mathrm{N})$, b: deney parçasının genişliği (mm), h: deney parçasının kalınlığı (mm).

$$
\sigma_{\mathrm{SE} 12}=\sigma_{\mathrm{SEM}}(1+\alpha(\mathrm{M}-12))\left(\mathrm{N} / \mathrm{mm}^{2}\right)
$$

Burada, $\mathrm{M}$ rutubet, $\alpha$ : düzeltme faktörü olup, bu değer 0.04 'dür.

Elastikiyet modülünün belirlenmesinde ise TS 2478 numaralı standart kullanılmıştır. Denemeler statik eğilme direncinin belirlenmesinde kullanılan aynı örnekler üzerinde Formüle (4)'e göre yapılmıştır.

$$
\sigma_{\mathrm{EM}}=\frac{\Delta \mathrm{F} \cdot \mathrm{L}^{3}}{\Delta \mathrm{f} \cdot 4 \cdot \mathrm{b} \cdot \mathrm{h}^{3}}\left(\mathrm{~N} / \mathrm{mm}^{2}\right)
$$

Burada; $\Delta \mathrm{F}$ : Elastik deformasyon bölgesinde uygulanan kuvvet farkı, $\Delta \mathrm{f}$ : Örnekteki eğilme miktarı, rutubetleri \%12'den farklı olan örneklerin \%12 rutubetteki elastikiyet modülleri $\left(\sigma_{\mathrm{EM} 12}\right)$ Formül (5)'e göre hesaplanmıştır.

$$
\sigma_{\mathrm{EM} 12}=\sigma_{\mathrm{EMM}}[1+\alpha(\mathrm{M}-12)]\left(\mathrm{N} / \mathrm{mm}^{2}\right)
$$

Burada: $\sigma_{\mathrm{EMM}}$ : M rutubetteki elastikiyet modülü $\alpha$ : düzeltme faktörü olup 0.02 'dir.

\subsection{3 Şok direncinin belirlenmesi}

Denemeler TS 2477 numaralı standarda göre yapılmıştır. Bu standarda göre; deney parçaları en kesiti 20x20 mm ve lif doğrultusunda boyu $300 \mathrm{~mm}$ olan kare dik prizma biçiminde her grup için 30 adet test örneği hazırlanmıştır. Şok direnci test makinesinde (Şekil 2-B) deney parçası bir çarpma ile kırılmıştır. Deneyin tamamlanmasından sonra kırılma bölgesine yakın bir yerden rutubet ve yoğunluk miktarının tayini için 20x20x30 mm boyutlarında örnek alınmıştır. Şok direnci aşağıdaki Formülle (6) hesaplanmıştır. Şok direnci tüm gruplarda radyal yüzeyde (teğet yönde) uygulanmıştır.

$$
\sigma_{\mathrm{SD}}=\frac{\mathrm{Q}}{\mathrm{bxh}}\left(\mathrm{kgm} / \mathrm{cm}^{2}\right)
$$

Burada; Q: deney parçasının kırılması için gerekli enerji $0.1(\mathrm{kgm}), \mathrm{b}$ ve h: deney parçasının radyal ve teğet yönlerdeki boyutları $(\mathrm{cm})$. Şok direncinin \%12 rutubete ayarlanması aşağıdaki formül (7) ile yapııııştır.

$$
\sigma_{\text {ŞD12 }}=\sigma_{\text {ŞDM }}(1+\alpha(M-12))
$$

Burada; $\sigma_{\text {ŞDM }}: M$ rutubet seviyesindeki şok direncidir, $\sigma_{\text {ŞD12 }}: \% 12$ rutubet seviyesindeki şok direncidir, $\alpha$ : düzeltme faktörü olup bunun değeri 0.025 'dir. 


\subsubsection{Basınç direncinin belirlenmesi}

Denemeler TS 2595 numaralı standarda göre yapılmıştır. Bu standarda göre deney parçaları lif doğrultusundaki boyu $30 \mathrm{~mm}$ ve en kesit kenarları $20 \mathrm{~mm}$ olan kare dik prizma biçiminde hazırlanmıştır. Öz odundan 150 ve diri odundan 150 adet test örneği hazırlanmıştır. Deney hızı teste başladıktan $1.5 \pm 0.5$ dakika sonra ezilme sınırına ulaşacak şekilde ayarlanmıştır. Deneyler Losenhausen model bir statik malzeme test cihazında yapılmıştır (Şekil 2-C). Deneyin tamamlanmasından sonra rutubet miktarının tayini için deney parçasının

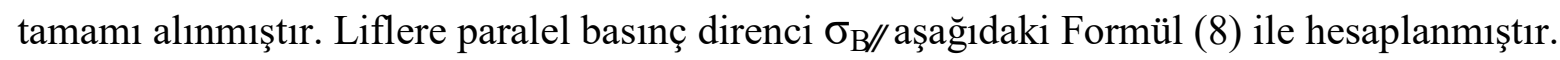

$$
\sigma_{\mathrm{B} / F} \frac{\mathrm{P}_{\max }}{\mathrm{axb}}\left(\mathrm{N} / \mathrm{mm}^{2}\right)
$$

Burada; $\mathrm{P}_{\max }$ : kırılma anında uygulanan maksimum yük $(\mathrm{N})$, a ve $\mathrm{b}$ : deney numunesinin genişlik ve kalınlığı $(\mathrm{mm}), \mathrm{M}$ rutubet miktarında belirlenen liflere paralel basınç direncinin $\% 12$ rutubet miktarına tahvili aşağıdaki formülle (9) yapılmıştır.

$$
\sigma_{\mathrm{B} / / 12}=\sigma_{\mathrm{B} / \mathrm{M}}(1+\alpha(\mathrm{M}-12))
$$

Burada; $\alpha$ : rutubet miktarı için düzeltme faktörü olup bu değer 0.05 'dir. M: odunun deney yapıldığı andaki rutubet miktarıdır.
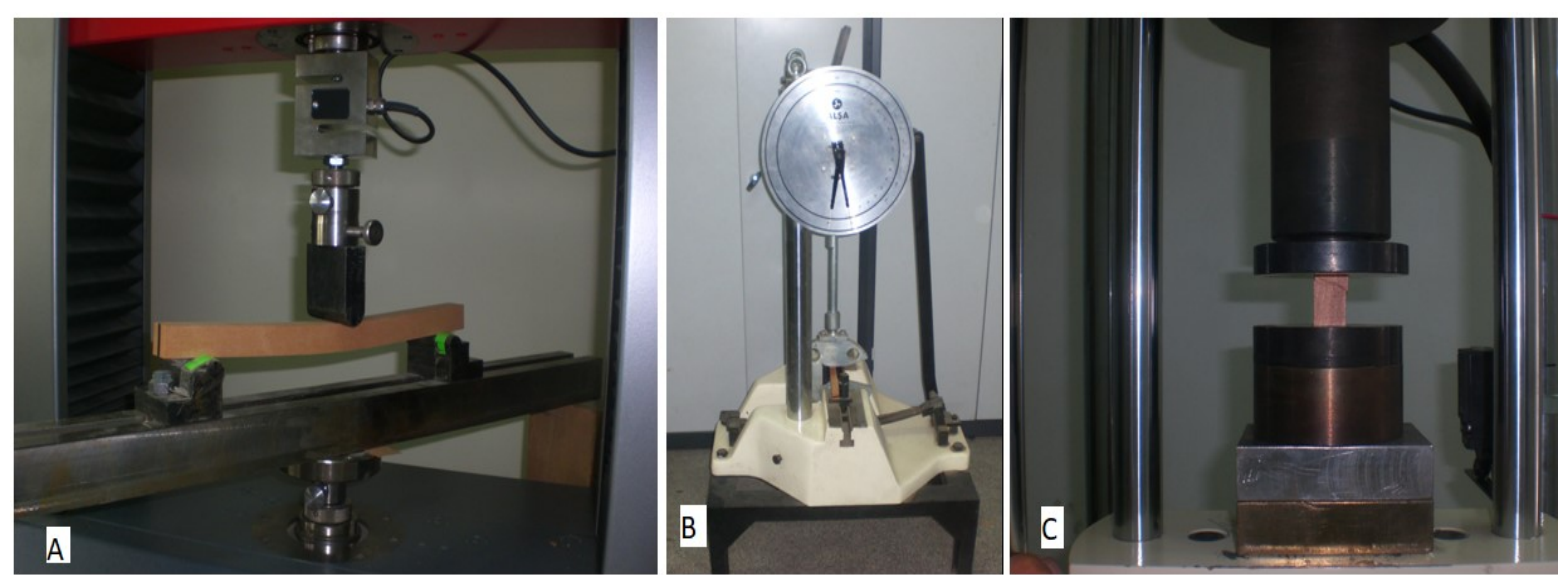

Şekil 2. Eğilme direnci (A), Şok direnci (B), Basınç direnci (C) test esnasındaki görüntü

\subsection{5 İstatistik değerlerin hesaplamalar}

Denemeler sonunda elde edilen tüm veriler Excel programına yüklenmiştir. Tüm test sonuçları bu programda hesaplanmıştır. Ayrıca, yoğunluk değerleri ile mekanik özellikler arasındaki ilişkiler, regresyon denklemleri ve belirtme katsayılarının hesaplanması ile yapılmıştır. Bu regresyon denklemleri ve belirtme katsayıları grafikler içerisinde verilmiştir. 


\section{Bulgular ve Tartışma}

Denemelerde kullanılan test örneklerinin ayrı ayrı hava kurusu yoğunluk değerleri hesaplanmış ve Çizelge 1'de verilmiştir. Çizelgede verilen yoğunluk değerleri incelendiğinde genel olarak kavak odununun yoğunluğunun kayın odunundan daha düşük olduğu görülmektedir. Çalışma planlanırken, önceki çalışmalar göz önüne alındığında bu sonuç beklenen bir sonuçtur. Bu konuda yapılan önceki çalışmalarda benzer sonuçlar kayın ve kavak odunu yoğunlukları için farklı araştırmacılar tarafından da belirlenmiştir. Ancak, Çizelgede verilen kavak öz odunu yoğunluğu diri odun yoğunluğundan daha düşüktür. Buna karşın kayın öz odunu yoğunluğu kayın diri odunundan daha yüksektir. Odun yoğunluğu üzerine yapılan çalışmalarda, ya ortalama yoğunluk hesaplanmakta yada özden çevreye doğru yoğunluk değişimi incelenmektedir. Bu şekilde yapılan çalışmalarda özden çevreye doğru yoğunluğun değiştiği birçok araştırmacı tarafından rapor edilmiştir (Malkoçoğlu 1994; Doğu 2000; Bao ve ark., 2001; Calvo ve ark., 2006; Kord ve ark., 2010; Kiaei 2011).Ağaç türleri bakımından bu şekildeki farklılıkların önemli bazı sebepleri bulunmaktadır. Örneğin; öz odun içerisinde yüksek oranda (enine kesit alanı bakımından) genç odun kısmı bulunmakta ise bu durumda öz odun yoğunluğu daha düşük çıkmaktadır (Kord ve ark., 2010; Kiaei 2011; Bal ve Bektaş 2012). Ancak, öz odun kısmında yüksek oranda reçine bulunmakta ise bu durumda öz odun yoğunluğu daha yüksek olabilmektedir (Bal ve ark. 2012). Bu ikinci durum özellikle doğal reçine kanalları içeren iğne yapraklı ağaçlar için söz konusudur. Geniş yapraklı ağaçlarda, özellikle bazı türlerde öz odun traheleri tüllerle dolu olmaktadır. Bu durumda, öz odun kısmı yoğunluğu daha yüksek olmaktadır (Malkoçoğlu 1994; Doğu 2000). Ağacın yetişme yerinde meydana gelen değişik diş etkenlerde, bu yoğunluk farklılıklarına sebep olabilmektedir. Örneğin, ormanda yapılan aralama kesimleri sonrası ağacın hızlı gelişmesi ile çap artımı hızlanmakta ve daha geniş yıllık halka oluşturmaktadır.

Çizelge 1. Test örneklerinin tam kuru yoğunluk değerleri $(\mathrm{kg} / \mathrm{m} 3)$

\begin{tabular}{|c|c|c|c|c|}
\hline İ.D. & $\begin{array}{c}\text { Kavak } \\
\text { öz odun }\end{array}$ & $\begin{array}{c}\text { Kavak } \\
\text { diri odun }\end{array}$ & $\begin{array}{c}\text { Kayın } \\
\text { öz odun }\end{array}$ & $\begin{array}{c}\text { Kayın } \\
\text { diri odun }\end{array}$ \\
\hline $\mathbf{x}$ & 323.7 & 377.3 & 632.5 & 616.2 \\
\hline ss & 29.1 & 31.3 & 46.6 & 48.6 \\
\hline $\mathbf{v}$ & 9 & 8.3 & 7.4 & 7.9 \\
\hline
\end{tabular}

İ.D.: istatistik değerler, $\mathrm{x}$ :aritmetik ortalama, ss: standart sapma, v: varyasyon katsayıs1

Eğilme testleri sonunda elde edilen bulgular Çizelge 2'de verilmiştir. Çizelgede verilen eğilme direnci testlerine ait aritmetik ortalama değerleri incelendiğinde kayın odununda elde edilen eğilme direncinin kavak odunundan elde edilenden daha yüksek olduğu görülmektedir. Ayrıca, kavak öz odununda elde edilen eğilme direnci kavak diri odunundan ve kayın diri odununda elde edilen eğilme direnci değeri ise kayın öz odununda daha düşük ölçülmüştür. $\mathrm{Bu}$ durumda, öz odun diri odun farklılığından kaynaklanan eğilme direnci farklarına yoğunluğun etkili olduğu söylenebilir.

Çizelge 2. Eğilme direnci testine ait bulgular $\left(\mathrm{N} / \mathrm{mm}^{2}\right)$

\begin{tabular}{|c|c|c|c|c|}
\hline İ.D. & $\begin{array}{c}\text { Kavak } \\
\text { öz odunu }\end{array}$ & $\begin{array}{c}\text { Kavak } \\
\text { diri odunu }\end{array}$ & $\begin{array}{c}\text { Kayın } \\
\text { öz odunu }\end{array}$ & $\begin{array}{c}\text { Kayın } \\
\text { diri odunu }\end{array}$ \\
\hline $\mathbf{x}$ & 45.8 & 64.1 & 98.3 & 95.7 \\
\hline SS & 5.2 & 5.2 & 12 & 13.7 \\
\hline $\mathbf{v}$ & 11.3 & 8.1 & 12.2 & 14.3 \\
\hline
\end{tabular}

İ.D.: istatistik değerler, x:aritmetik ortalama, ss: standart sapma, v: varyasyon katsayıs1 
Hava kurusu yoğunlukla eğilme direnci arasında belirlenen regresyon denklemleri ve belirtme katsayısı $\left(\mathrm{R}^{2}\right)$ değeri Şekil 3'de verilmiştir. Şekilde verilen grafikte görüldüğü gibi, her iki ağaç türü içinde regresyon ilişkisi pozitif yönlü lineer bir ilişkidir. $\mathrm{R}^{2}$ belirtme katsayısı kavak odununda 0.92 ve kayın odununda 0.64 olarak hesaplanmıştır. Bu sonuçlara göre her iki odun türünde yoğunluk değeri ile eğilme direnci arasında güçlü bir ilişki olduğu söylenebilir. Odunun mekanik özellikleri üzerine yapılan bazı önceki çalışmalarda da benzer sonuçlar rapor edilmiştir (Malkoçoğlu 1994; Bektaş 1997; Bektaş ve ark., 2002; Kiaei 2011).

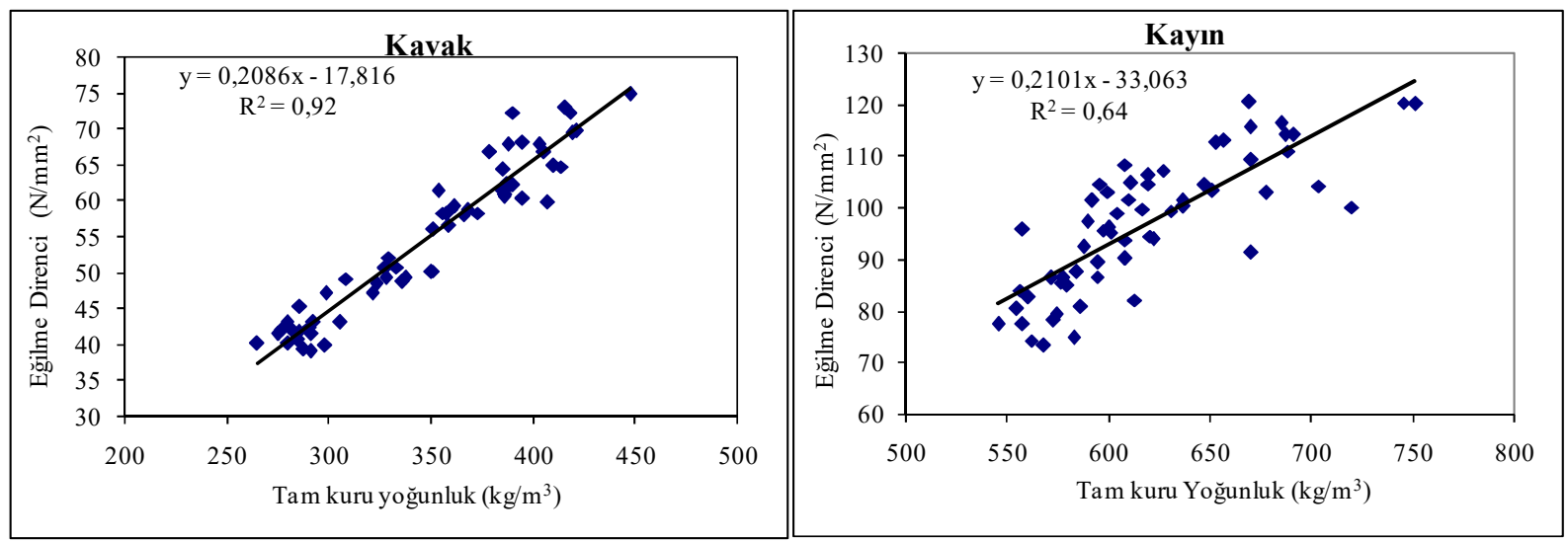

Şekil 3. Kavak ve kayın odunlarında eğilme direnci ile tam kuru yoğunluk arasındaki ilişki

Çizelge 3'de elastikiyet modülü testine ait bulgular verilmiştir. Çizelge incelendiğinde kavak odunu elastikiyet modülü değerlerinin kayın odunundan daha düşük olduğu görülmektedir. Her iki ağaç türünde de öz odun ile diri odun test örnekleri arasında önemli farklılıklar vardır. Eğilme direncine ait aritmetik ortalama değerlerinde olduğu gibi, elastikiyet modülü testine ait bulgularda da benzer sonuçlar elde edilmiştir. Kavak diri odununu kavak öz odunundan ve kayın öz odunu kayın diri odunundan daha yüksek elastikiyet modülüne sahiptir.

Çizelge 3. Elastikiyet modülüne ait bulgular $\left(\mathrm{N} / \mathrm{mm}^{2}\right)$

\begin{tabular}{|c|c|c|c|c|}
\hline İ.D. & $\begin{array}{c}\text { Kavak } \\
\text { öz odunu }\end{array}$ & $\begin{array}{c}\text { Kavak } \\
\text { diri odunu }\end{array}$ & $\begin{array}{c}\text { Kayın } \\
\text { öz odunu }\end{array}$ & $\begin{array}{c}\text { Kayın } \\
\text { diri odunu }\end{array}$ \\
\hline $\mathbf{x}$ & 4357 & 5882 & 8710 & 8306 \\
\hline ss & 489.8 & 430.3 & 1270 & 1270 \\
\hline $\mathbf{v}$ & 11.2 & 7.3 & 14.6 & 15.3 \\
\hline
\end{tabular}

İ.D.: istatistik değerler, x:aritmetik ortalama, ss: standart sapma, v: varyasyon katsayıs1

Elastikiyet modülü ile tam kuru yoğunluk değeri arasındaki ilişkiyi gösteren grafik, regresyon denklemi ve belirtme katsayısı Şekil 4'de verilmiştir. Şekilde verilen grafikler incelendiğinde yoğunluk ile elastikiyet modülü arasında artan doğrusal bir ilişki olduğu görülmektedir. Ayrıca, ilişkinin gücü $\mathrm{R}^{2}$ belirtme katsayıları incelendiğinde kavak odununda 0.93 ve kayın odununda 0.68 olarak belirlendiği görülmektedir. Bu verilere göre tam kuru yoğunluk ile elastikiyet modülü arasında oldukça güçlü bir ilişki olduğu söylenebilir. Odunun elastikiyet modülü üzerine yapılan bazı önceki çalışmalarda da benzer sonuçlar rapor edilmiştir (Malkoçoğlu 1994; Bektaş 1997; Bektaş ve ark., 2002; Kiaei 2011). Belirtme katsayısının kavak odununda kayın odunundan daha yüksek olmasının nedeni ise kavak odununda öz odun ile diri odun arasındaki farkın kayın odunundaki farktan daha yüksek olmasından (Çizelge 1'de görüldüğü gibi) kaynaklandığı söylenebilir. 

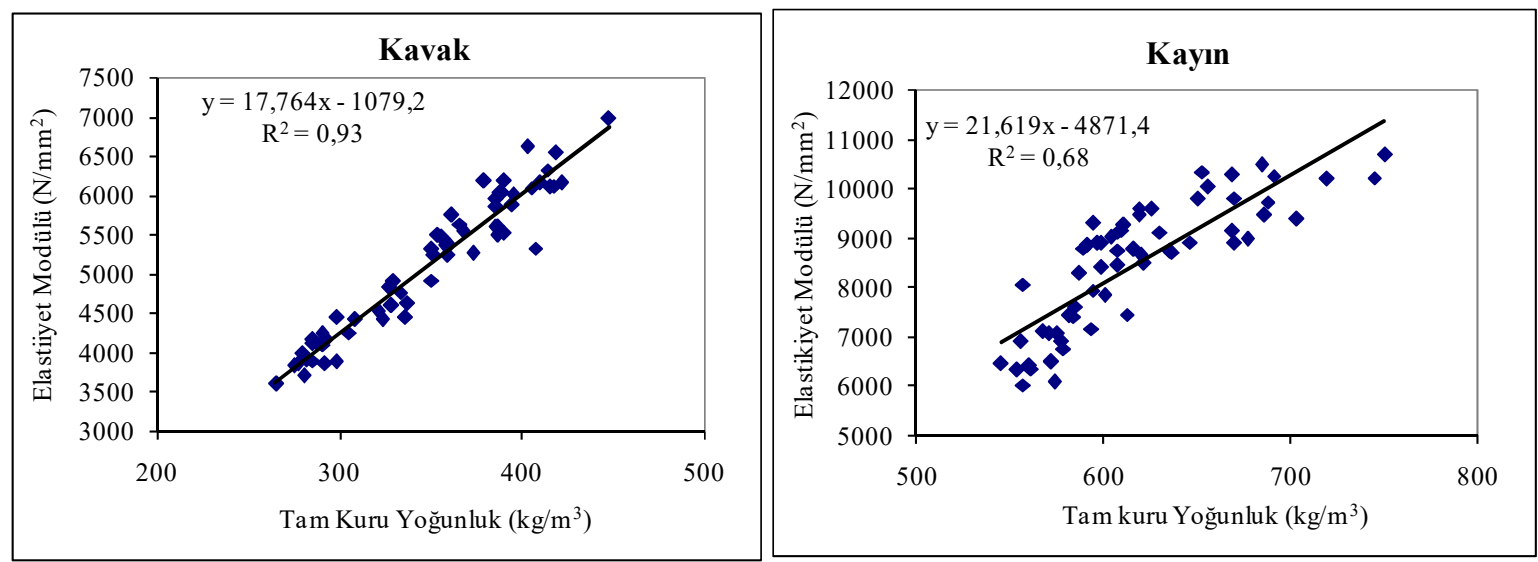

Şekil 4. Kavak ve kayın odunlarında elastikiyet modülü ile tam kuru yoğunluk arasındaki ilişki

Basınç direnci testine ait aritmetik ortalama, standart sapma ve varyasyon katsayısı değerleri Çizelge 4'de verilmiştir. Çizelgede verilen kavak öz odunu basınç direnci değerlerinin kavak diri odunundan düşük olduğu ve kayın diri odunun basınç direncinin ise kayın öz odunundan düşük olduğu görülmektedir. Eğilme direnci ve elastikiyet modülüne ait sonuçlara benzer sonuçlar elde edilmiştir. Bazı istisnalar hariç, genel olarak odunun mekanik özellikleri ile yoğunluğu arasında artan doğrusal bir ilişki olduğu bilinmektedir. Bu konuda yapılan önceki çalışmalarda da benzer sonuçlar rapor edilmiştir (Malkoçoğlu 1994; Bektaş 1997; Bektaş ve ark., 2002; Kiaei 2011; Bal ve ark. 2012). Şok direnci gibi diğer bazı testlerde ise, odun hücrelerinin uzunluğu ve hücre çeperinin kimyasal içeriğinin ölçülen mekanik özellik üzerine etkili olduğu da bilinmektedir. Ancak, basınç direnci testinde en önemli faktör yoğunluktur. Bu ilişkiyi gösteren grafik Şekil 5'de verilmiştir. Şekildeki belirtme katsayıları dikkate alındığında artan güçlü bir ilişki olduğu görülmektedir.

Çizelge 4. Basınç direnci testine ait bulgular $\left(\mathrm{N} / \mathrm{mm}^{2}\right)$

\begin{tabular}{|c|c|c|c|c|}
\hline İ.D. & $\begin{array}{c}\text { Kavak } \\
\text { oz odunu }\end{array}$ & $\begin{array}{c}\text { Kavak } \\
\text { diri odunu }\end{array}$ & $\begin{array}{c}\text { Kayın } \\
\text { öz odunu }\end{array}$ & $\begin{array}{c}\text { Kayın } \\
\text { diri odunu }\end{array}$ \\
\hline $\mathbf{x}$ & 31.6 & 37.8 & 55.1 & 53.3 \\
\hline ss & 3.5 & 3.8 & 6.7 & 6.6 \\
\hline $\mathbf{v}$ & 11.1 & 10 & 12.1 & 12.4 \\
\hline
\end{tabular}

İ.D.: istatistik değerler, x:aritmetik ortalama, ss: standart sapma, v: varyasyon katsayıs1

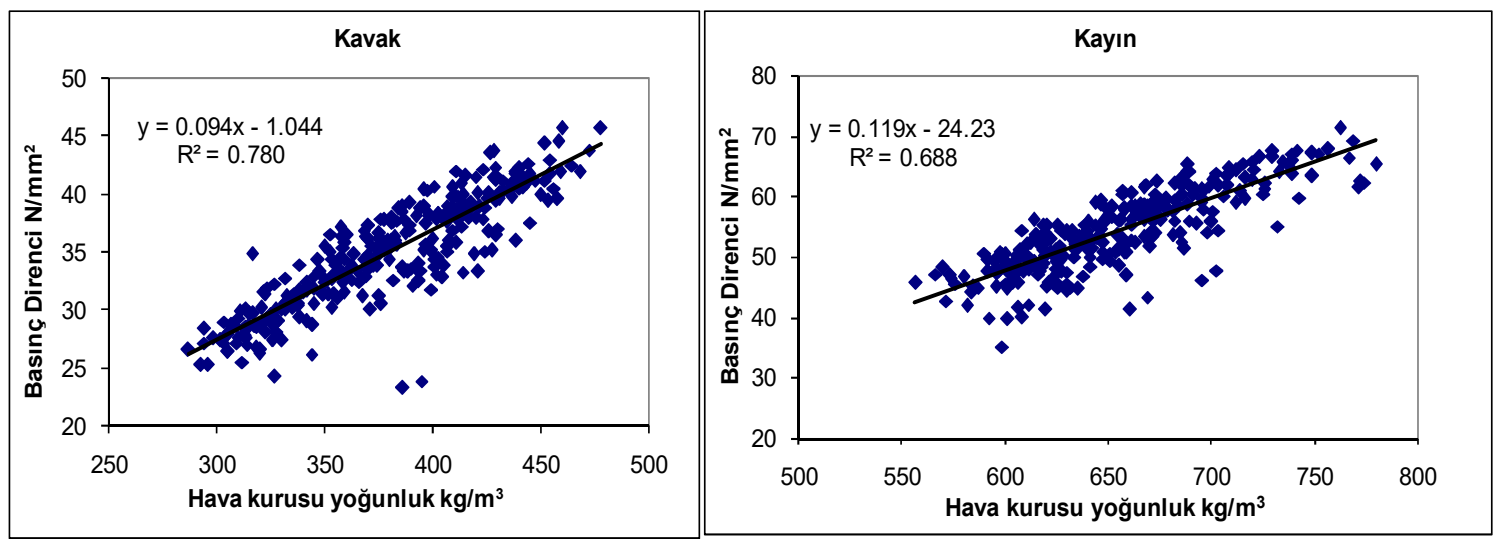

Şekil 5. Kavak ve kayın odunlarında basınç direnci ile hava kurusu yoğunluk arasındaki ilişki 
Şok direnci testine ait bulgular Çizelge 5'de verilmiştir. Çizelgede verilen bulgular incelendiğinde, kavak diri odununun kavak öz odunundan ve kayın diri odununun kayın öz odunundan daha yüksek şok direncine sahip olduğu görülmektedir. Bu çalışmada verilen diğer mekanik özelliklerle karşılaştırıldığında şok direnci sonuçlarının kayın odununda diğerlerinden farklı olduğu görülmektedir. Eğilme direnci, elastikiyet modülü ve basınç direncine ait bulgularda kayın öz odunu kayın diri odunundan daha yüksek performansa sahiptir. Ancak, şok direncinde bu durum farklı sonuçlanmıştır. Bunun önemli sebeplerinden birisinin kayın öz odununda bulunan liflerin diri odun kısmındaki liflerden daha kısa olmasıdır. Daha önce birçok farklı ağaç türü üzerinde yapılan çalışmalarda, ağaç enine kesitinde özden çevreye doğru olan yönde hücre boylarının uzadığı belirlenmiştir (Doğu 2000; Bao ve ark. 2001). Şok direnci sonrasında kırılma şekilleri bakımından yapılan görsel incelemelerde 3 mm'den kısa kıymıklı kırılmaların gevrek odunu, 3 mm'den uzun kıymıklı odunların ise esnek odunun işareti olduğu ilgili TS standardında belirtilmiştir. Bu konuda yapılan bazı önceki çalışmalarda da benzer sonuçlar rapor edilmiştir (Malkoçoğlu 1994; Bektaş 1997; Bektaş ve ark., 2002; Bal ve ark., 2012). Hücre çeperi bileşenlerinden lignin oranı da şok direncini etkilemektedir. Lignin miktarının artması ile şok direnci düşmektedir. Şok direnci denemelerinde kırılmaların lignin miktarının fazla olduğu orta lamelde gerçekleştiği belirtilmiştir ( Kollman ve Cote 1968; Bozkurt ve Erdin 1997).

Çizelge 5. Şok direnci testine ait bulgular $\left(\mathrm{kgm} / \mathrm{cm}^{2}\right)$

\begin{tabular}{|c|c|c|c|c|}
\hline İ.D. & $\begin{array}{c}\text { Kavak } \\
\text { öz odunu }\end{array}$ & $\begin{array}{c}\text { Kavak } \\
\text { diri odunu }\end{array}$ & $\begin{array}{c}\text { Kayın } \\
\text { öz odunu }\end{array}$ & $\begin{array}{c}\text { Kayın } \\
\text { diri odunu }\end{array}$ \\
\hline $\mathbf{x}$ & 0.300 & 0.459 & 0.600 & 0.840 \\
\hline $\mathbf{s}$ & 0.074 & 0.112 & 0.166 & 0.363 \\
\hline $\mathbf{v}$ & 24.81 & 24.46 & 27.64 & 43.25 \\
\hline
\end{tabular}

İ.D.: istatistik değerler, $\mathrm{x}$ :aritmetik ortalama, s: standart sapma, v: varyasyon katsayıs1

Kavak ve kayın odunlarında, şok direnci ile tam kuru yoğunluk değerleri arasındaki ilişkiyi gösteren grafik Şekil 6'da verilmiştir. Bu ilişkiye ait regresyon denklemleri ve belirtme katsayıları da şekil içinde verilmiştir. Grafik incelendiğinde şok direnci ile tam kuru yoğunluk arasında güçlü bir ilişki olduğu görülmektedir. Benzer sonuçlar Malkoçoğlu (1994), Bektaş (1997), Bektaş ve ark., (2002), Bal ve ark. (2012) tarafından da tespit edilmiştir. Kavak odununda bu ilişkinin gücü kayın odunundan yüksektir. Bunun önemli bir sebebinin, yukarda anlatıldığı gibi, kayın diri odununda lif uzunluklarının daha yüksek olması ve öz odununda lignin miktarının fazla olmasından kaynaklandığı söylenebilir.
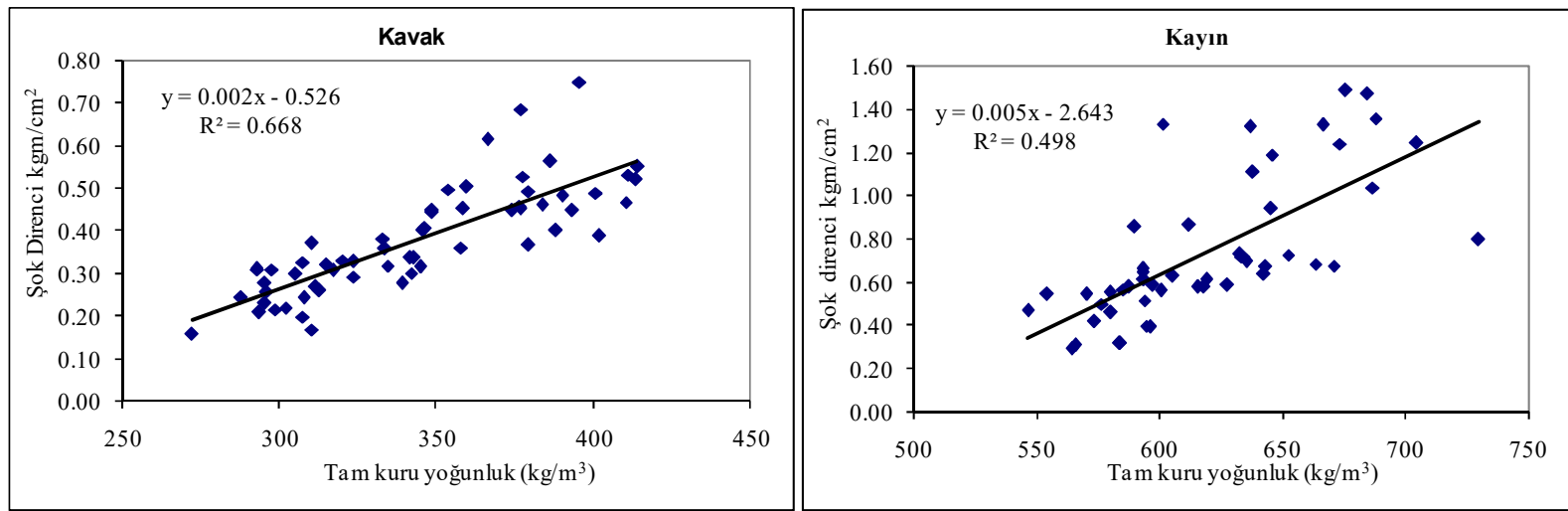

Şekil 6. Kavak ve kayın odunlarında şok direnci ile tam kuru yoğunluk arasındaki ilişki 


\section{Sonuçlar}

Çalışma sonunda elde edilen bulgulara göre şu sonuçlar söylenebilir;

- Kavak ve kayın öz ve diri odunlarında yoğunluk arttıkça eğilme direnci, elastikiyet modülü, basınç direnci ve şok direnci artmaktadır.

- Şok direnci hariç, diğer mekanik özelliklerde kavak diri odununda ve kayın öz odununda daha yüksek mekanik özellikler belirlenmiştir.

- Tam kuru yoğunluk ile mekanik özellikler arasında artan doğrusal güçlü bir ilişki belirlenmiştir.

- Şok direncinin, kayın diri odununda öz odunundan daha yüksek olduğu belirlenmiştir. Bunun önemli bir nedeninin lif uzunluğu ve kimyasal içeriğinden olduğu söylenebilir. Yük taşıyan kullanım yerlerinde ve özellikle esnek ağaç malzemenin arandığı kullanım yerlerinde diri odundan elde edilen malzemenin kullanılması önerilir.

\section{Teşekkü r}

Bu çalışma, Kahramanmaraş Sütçü İmam Üniversitesi, Bilimsel Araştırma Projeleri Yönetim Birimi Başkanlığı tarafından 2009/3-2D numaralı proje kapsamında desteklenmiştir. $\mathrm{Bu}$ destekten dolayı KSÜ BAP birimine teşekkür ediyoruz.

\section{Kaynaklar}

Ay,N., ve Şahin, H. (1998), An investigation on internal morphological proporties of sapwood and heartwood of oriental spruce [Picea orientalis (L.) Link.], Turkish Journal of Agriculture and Forestry, 22(2), 203-208.

Bal, B.C., (2012), Genç odun ve olgun odunun lif morfolojisindeki farkl1lıklar üzerine bir araştırma, Düzce Üniversitesi Ormancılık Dergisi, 8(2), 29-36

Bal, B.C., and Bektaş, İ. (2012), The physical properties of heartwood and sapwood of Eucalyptus Grandis, Proligno, 8(4), 35-43.

Bal, B. C., and Bektaş İ. (2013), The mechanical properties of heartwood and sapwood of flooded gum (Eucalyptus grandis ) grown in Karabucak, Turkey. Düzce Üniveristesi, Ormancılık Dergisi, 9(1), 71-76.

Bal, B. C., Bektaş İ.,ve Kaymakçi, A. (2012), Toros sedirinde genç odun ve olgun odunun bazı fiziksel ve mekanik özellikleri, KSÜ Mühendsilik Bilimleri Dergisi, 15(2), 17-27.

Bal, B.C., ve Bektaş, İ, (2018), Kayın ve kavak odunlarında fiziksel özelliklerle yoğunluk ilişkisinin belirlenmesi, Mobilya ve Ahşap Malzeme Araştırmaları Dergisi, 1(1), 1-10.

Bao, F. C., Jiang, Z. H., Jiang, X. M., Lu, X. X., Luo, X. Q., and Zhang, S. Y. (2001), Differences in wood properties between juvenile wood and mature wood in 10 species grown in China, Wood Science and Technology, 35(4), 363-375.

Bektaş, İ. (1997), Kızılçam odununun teknolojik özellikleri ve yörelere göre değişimi, İÜ, Fen Bilimleri Enstitüsü, Doktora Tezi, İstanbul.

Bektaş, İ., ve Güler, C. (2001), Andırın yöresi doğu kayını (Fagus orientalis L.) odununun bazı fiziksel özelliklerinin belirlenmesi, Turk J Agric For, 25(4), 209-215.

Bektaş, İ., Güler, C., and Baştürk, M. A. (2002), Principal mechanical properties of eastern beech wood (Fagus orientalis L.) naturally grown in Andirın northeastern mediterranean region of Turkey, Turk J Agric For, 26(2002), 147-154. 
Bozkurt, Y., ve Erdin, N. (1995), Yoğunluk ile mekanik özellikler arasındaki ilişkiler. İstanbul Üniversitesi Orman Fakültesi Dergisi, 45(2), 11-34.

Bozkurt, Y., ve Erdin, N. (1997), Ağaç teknolojisi, İstanbul Üniversitesi, Orman Fakültesi Yayınlarl, No 445, İstanbul,1997.

Bozkurt, Y., ve Göker, Y. (1996), Fiziksel ve mekanik ağaç teknolojisi, Y1lmaz Bozkurt, Yener Göker İ̈̈, Orman Fakültesi Yayınlart, No:3944, İstanbul.

Calvo, CF, Cotrina, A.D., Cuffré, A.G., Piter, J. C., Stefani P. M., Torrán, E.A., (2006),Radial and axial variation of swelling, anisotropy and density, in Argentinean Eucalyptus Grandis, Maderas Ciencia y tecnología 8(3), 159-168.

Çetin, N. S., Birinci, E., ve Özmen, N. (2010), Doğu ladini (Picea orlentalis) ve sarıçam (Pinus sylvestris) öz ve diri odunlarının kahverengi (Coniophora puteana) ve beyaz (trametes versıcolor) çürüklük mantarlarına karşı dayanımının araştırılması. III. Ulusal Karadeniz Ormanc1lık Kongres,20-22 Mayıs 2010, Cilt: IV Sayfa: 1639-1648.

Doğu, A.D. (2000), Batı karadeniz bölgesinde yetişen adi ceviz (Juglans regia L.), odununun bazı anatomik ve fiziksel özellikleri, İÜ, Fen Bilimleri Enstitüsü. Doktora Tezi.

İstek, A, Gülsoy, S. K., ve Eroğlu, H. (2010), karaçam öz odunu ve diri odunu lifsel özelliklerinin karşılaştırılması, III. Ulusal Karadeniz Ormancılık Kongresi,20-22 Mayıs 2010, Cilt: V, Sayfa: 1916-1924.

Kiaei, M., (2011),Anatomical, physical, and mechanical properties of eldar pine (Pinus eldarica) grown in the Kelardasht region, Turk J Agric For. 35 (2011), 31-42.

Kord, B., Kialashaki A., and Kord B. (2010), The within-tree variation in wood density and shrinkage and their relationship in Populus euramericana, Turk J Agric For, 34, 1-6.

Kollmann, F., and Cote, W. A. (1968), Principles of wood science and technology, Springer Verlag.

Malkoçoğlu, A. (1994), Doğu kayını (Fagus Orientalis L.) odununun teknolojik özellikleri, Karadeniz Teknik Üniversitesi, Fen Bilimleri Enstitüsü, Doktora Tezi, Trabzon.

Örs, Y., ve Keskin, H. (2001), Ağaç malzeme bilgisi, Gazi üniversitesi ders kitabı, S:77, Ankara.

Pliura, A., Yu, Q., Zhang, S. Y., and Mackay, J. (2005), Variation in wood density and shrinkage and their relationship to growth of selected young poplar hybrid crooes. Agricultural and Environmental Database, 51(5), 472.

TS 2470, (1976), Odunda fiziksel ve mekaniksel deneyler için numune alma metotları ve genel özellikler,TSE, Ankara.

TS 2471, (1976), Odunda fiziksel ve mekaniksel deneyler için rutubet miktarı tayini, TSE, Ankara.

TS 2472, (1976), Odunda Fiziksel ve Mekaniksel Deneyler İçin Birim Hacim Ağırlığı Tayini, TSE, Ankara.

TS 2474, (1976), Odunun statik eğilme dayanımının tayini, TSE, Ankara.

TS 2477, (1976), Odunun çarpmada eğilme dayanımının tayini, TSE, Ankara.

TS 2478, (1976), Odunun statik eğilmede elastiklik modülünün tayini, TSE, Ankara.

TS 2595, (1977), Odunun liflere paralel doğrultuda basınç dayanımının tayini, TSE, Ankara. 